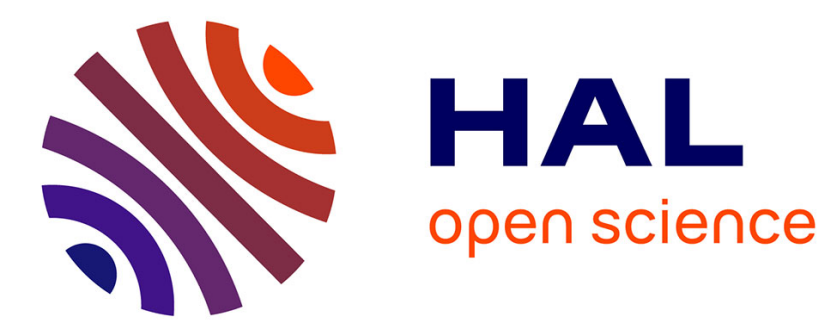

\title{
Mechanistic insight into the role of \\ Poly(ADP-ribosyl)ation in DNA topology modulation and response to DNA damage
}

Bakhyt Matkarimov, Dmitry Zharkov, Murat Saparbaev

\section{- To cite this version:}

Bakhyt Matkarimov, Dmitry Zharkov, Murat Saparbaev. Mechanistic insight into the role of Poly(ADP-ribosyl)ation in DNA topology modulation and response to DNA damage. Mutagenesis, In press, 35 (1), pp.107-117. 10.1093/mutage/gez045 . hal-02392725

\section{HAL Id: hal-02392725 \\ https://hal.science/hal-02392725}

Submitted on 4 Dec 2019

HAL is a multi-disciplinary open access archive for the deposit and dissemination of scientific research documents, whether they are published or not. The documents may come from teaching and research institutions in France or abroad, or from public or private research centers.
L'archive ouverte pluridisciplinaire HAL, est destinée au dépôt et à la diffusion de documents scientifiques de niveau recherche, publiés ou non, émanant des établissements d'enseignement et de recherche français ou étrangers, des laboratoires publics ou privés. 


\title{
Mechanistic insight into the role of Poly(ADP-ribosyl)ation in DNA topology modulation and response to DNA damage
}

\author{
Bakhyt T. Matkarimov ${ }^{1}$, Dmitry O. Zharkov ${ }^{2,3}$ and Murat K. Saparbaev ${ }^{4, *, \odot}$
}

'National Laboratory Astana, Nazarbayev University, 53 Kabanbay Batyr Ave, Astana 010000, Kazakhstan, ${ }^{2}$ SB RAS Institute of Chemical Biology and Fundamental Medicine, 8 Lavrentieva Ave., Novosibirsk 630090, Russia, ${ }^{3}$ Novosibirsk State University, 2, Pirogova str., Novosibirsk 630090, Russia and ${ }^{4}$ Groupe "Réparation de l'ADN», Equipe Labellisée par la Ligue Nationale Contre le Cancer, CNRS UMR8200, Université Paris-Sud, Gustave Roussy Cancer Campus, F-94805 Villejuif Cedex, France

*To whom correspondence should be addressed. Tel: +33 1 42115404; Fax: +33 1 42115244; Email: murat.saparbaev@ gustaveroussy.fr

Received 17 June 2019; Editorial decision 10 November 2019; Accepted 12 November 2019.

\begin{abstract}
Genotoxic stress generates single- and double-strand DNA breaks either through direct damage by reactive oxygen species or as intermediates of DNA repair. Failure to detect and repair DNA strand breaks leads to deleterious consequences such as chromosomal aberrations, genomic instability and cell death. DNA strand breaks disrupt the superhelical state of cellular DNA, which further disturbs the chromatin architecture and gene activity regulation. Proteins from the poly(ADPribose) polymerase (PARP) family, such as PARP1 and PARP2, use NAD+ as a substrate to catalyse the synthesis of polymeric chains consisting of ADP-ribose units covalently attached to an acceptor molecule. PARP1 and PARP2 are regarded as DNA damage sensors that, upon activation by strand breaks, poly(ADP-ribosyl)ate themselves and nuclear acceptor proteins. Noteworthy, the regularly branched structure of poly(ADP-ribose) polymer suggests that the mechanism of its synthesis may involve circular movement of PARP1 around the DNA helix, with a branching point in PAR corresponding to one complete $360^{\circ}$ turn. We propose that PARP1 stays bound to a DNA strand break end, but rotates around the helix displaced by the growing poly(ADP-ribose) chain, and that this rotation could introduce positive supercoils into damaged chromosomal DNA. This topology modulation would enable nucleosome displacement and chromatin decondensation around the lesion site, facilitating the access of DNA repair proteins or transcription factors. PARP1-mediated DNA supercoiling can be transmitted over long distances, resulting in changes in the high-order chromatin structures. The available structures of PARP1 are consistent with the strand breakinduced PAR synthesis as a driving force for PARP1 rotation around the DNA axis.
\end{abstract}

\section{Introduction}

A variety of exogenous and endogenous factors can damage cellular DNA, resulting in nucleobase modifications and DNA strand breaks (1). Reactive oxygen species abstract hydrogen from deoxyribose carbons leading to single- and double-strand DNA breaks (SSBs and DSBs, respectively) (2). DNA strand breaks can be also generated indirectly during DNA excision repair of oxidised bases, replication fork collapse and topoisomerase action (3). If not detected and repaired, DNA strand breaks can have detrimental consequences, including gross chromosomal rearrangements, genomic instability and cell death. The poly(ADP-ribose) polymerase (PARP) family of proteins, also called the diphtheria toxin-like ADP-ribosyltransferase (ARTD) family, includes 17 known members identified by homology search. The best-studied PARP enzymes, PARP1 and PARP2, catalyse the synthesis of polymers of ADP-ribose (PAR) covalently attached to acceptor proteins using nicotinamide adenine dinucleotide 


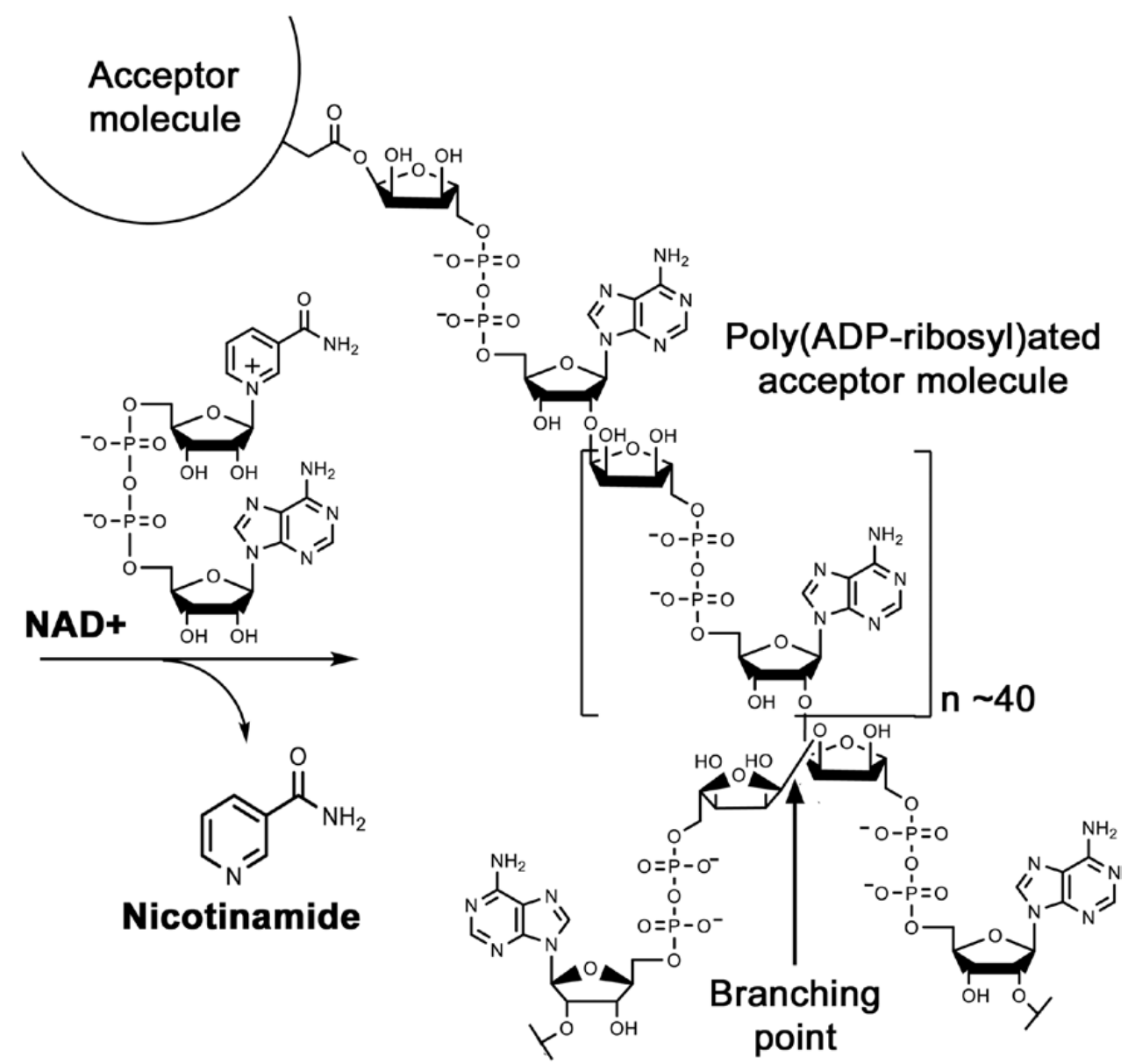

Figure 1. The synthesis of linear and branched polymers of poly(ADP-ribose). PARP1 cleaves NAD+ and transfer the ADP-ribose moiety to covalently modify attach to proteins or terminal phosphate residue of DNA. The synthesis of linear PAR chains is carried out through formation of $1^{\prime \prime}-2^{\prime}$ glycosidic bonds and branching points are made via $1^{\prime \prime \prime}-2^{\prime \prime}$ glycosidic bonds. The polymer of up to 300 units with branching points approximately every 40 units is assembled ( 84 ).

$\left(\mathrm{NAD}^{+}\right)$as a substrate (4-6) (Figure 1). It is commonly agreed that PARP1 and PARP2 are DNA damage sensors that are activated by binding to strand discontinuities. Upon the activation, PARPs poly-ADP-ribosylate (PARylate) themselves and other nuclear proteins, which in turn regulates the function of the modified proteins. Exposure of cells to DNA-damaging agents leads to the activation of PARP1-catalysed self-PARylation and modification of nuclear proteins such as histones (7). The ADP-ribose polymer, which has a complex branched structure, confers a negative charge and promotes electrostatic repulsion of PARylated proteins thus decreasing their affinity for DNA $(8,9)$. PARP-catalysed covalent PARylation is a reversible process since PAR is rapidly degraded by poly(ADPribose) glycohydrolase (PARG). PARG, encoded by a single gene in mammals, is the only enzyme capable of specific hydrolysis of the ribose-ribose bonds. Disruption of the PARG gene in mice is embryonic lethal (10), and PARG-deficient cells exhibit increased cell death and impaired repair of DNA base damage and strand breaks (11-13), indicating that accumulation of PARylated macromolecules is highly toxic to the cell.

Mammalian PARP1 accounts for $80-90 \%$ of measurable poly(ADP-ribose) synthesis following DNA damage. PARP1 is a multi-domain protein consisting of six distinct modules: two DNAbinding zinc finger domains ( $\mathrm{ff} 1$ and $\mathrm{Zf2}$ ), a zinc-binding PADR1 (or Zf3) domain, a BRCA1 C-terminal (BRCT) motif followed by a linker containing a cluster of glutamic acid residues serving as
ADP-ribose acceptor sites, a DNA-binding WGR domain, and a C-terminal catalytic (CAT) domain composed of a regulatory helical subdomain and an ADP-ribosyl transferase subdomain (ART). The ART domain contains the NAD+-binding site and catalyses cleavage of $\mathrm{NAD}^{+}$into nicotinamide and ADP-ribose; the latter is then polymerised and forms a branched PAR structure covalently attached to an acceptor moiety (14). PARP2 lacks zinc fingers and relies exclusively on its WGR domain for DNA binding; it also recognises a distinct set of DNA structures as compared to PARP1, suggesting that the two PARPs have non-overlapping functions in DNA repair $(15,16)$.

Small non-bulky DNA lesions are removed via two overlapping pathways: DNA glycosylase-initiated base excision repair (BER) and AP endonuclease-mediated nucleotide incision repair (NIR) (17). In BER, a DNA glycosylase excises the modified base, leaving either an apurinic/apyrimidinic (AP) site or an SSB with a modified 3' sugar-phosphate group that must be removed prior to the gap-filling synthesis step. In NIR, a damage-specific AP endonuclease nicks the backbone $5^{\prime}$ to the lesion in a DNA glycosylase-independent manner, producing an SSB with a $3^{\prime}$-hydroxyl terminus and a $5^{\prime}$ dangling damaged nucleotide (18). Thus, DNA strand breaks generated either directly or as intermediates of DNA excision repair contain 3'- or 5 -blocking groups or both and therefore require additional cleansing steps before DNA repair synthesis and ligation. Mice deficient in PARPs exhibit a phenotype hypersensitive to ionising radiation and 
alkylating agents $(19,20)$. These observations are indicative of the crucial role of PARPs in the processing of both directly produced strand breaks and BER/NIR intermediates in vivo.

Separation of the PARP1-catalysed PARylation from its DNA binding function results in the inhibition of SSB repair and increased sensitivity of the cells to DNA-damaging agents (21). Moreover, the inhibition of PARP1 and PARP2 by certain drugs can result in the formation of trapped PARP-DNA complexes that are more cytotoxic than unrepaired SSBs in PARP knockout cells (22). These data suggest that both PARP functions-PARylation of acceptor molecules and detection of DNA strand breaks-are essential to counteract DNA damage in vivo, and that separation of these activities can induce lethal DNA lesions. In the currently accepted paradigm, the PARP enzymes first detect and bind a DNA strand break and then ADP-ribosylate either themselves or a number of nuclear proteins in the vicinity of the break (4). In this classical model, damaged DNA is only a 'cofactor' for PARPs. It was proposed that PARylation of acceptor proteins promotes SSB repair through the recruitment of the XRCC1 protein and the assembly of XRCC1 nuclear foci at the lesion site (23). XRCC1, a key scaffold protein in the BER pathway, binds to SSB and then recruits and activates (through protein-protein interactions) the DNA repair factors necessary for end cleansing, DNA synthesis and ligation (24). Furthermore, it was postulated that at lower levels of cellular DNA damage PARPs can regulate DNA repair by recruiting proteins to strand breaks, while more severe DNA damage causes PARPs to promote cell death by necrosis, apoptosis, or both $(4,25)$.

The widespread presence of PARP proteins in eukaryotes and their unique post-translational modification activity could be ultimately owed to two main raisons d'être: first, packing of nuclear DNA into chromatin, a highly hierarchical structure with several levels of organisation (26), and second, the sheer size of genomes of higher eukaryotes. Notably, eukaryotes with genomes less than $100 \mathrm{Mb}$ such as yeast lack PARP proteins. Chromatin structure imposes restrictions on DNA-protein interactions, and several studies have shown that chromatin packaging restricts the ability of the DNA repair machinery to access the sites of DNA damage $(27,28)$. It is generally agreed that PARylation of nuclear proteins is required for the regulation of DNA repair and transcription in the context of large genome size and chromatin organisation in the nucleus $(29,30)$.

\section{ADP-ribosylation of DNA strand break termini}

Recent studies have uncovered a previously unknown phenomenon of post-replicative DNA modification via ADP-ribosylation of strand break termini in short-duplex DNA oligonucleotides; this reaction is catalysed by PARP1, PARP2 and PARP3 (31-34) (Figure 2). PARP1 and PARP2 catalyse covalent addition of ADPribose units to $5^{\prime}$ - and $3^{\prime}$-teminal phosphates and to $2^{\prime}-\mathrm{OH}$ termini of modified nucleotides at DNA strand breaks, producing covalent PAR-DNA adducts (31). PARP1 preferentially ADP-ribosylates DNA strand break termini containing terminal phosphates or 2'$\mathrm{OH}$ group in gapped, recessed DNA duplexes (Figure 2B), whereas PARP2 preferentially acts on 5 -terminal phosphates at DSB termini of nicked DNA (Figure 2B). Also, PARP3 can effectively generate mono(ADP-ribosyl)ated DNA (MAR-DNA) adducts covalently linked to terminal phosphate residues at DSB and SSB in DNA substrate which contain a $5^{\prime}$ phosphorylated nick $(33,34)$, thus sharing its substrate specificity with PARP2. In a reverse process, PARG efficiently restores native DNA structure by hydrolysing PAR/MARDNA adducts. Biochemical and mass spectrometry analyses of the adducts demonstrated that PARPs can utilise DNA termini as an alternative to 2'-hydroxyl of ADP-ribose and protein acceptor residues to catalyse PAR/MAR chain initiation either via the $2^{\prime}, 1^{\prime \prime}-\mathrm{O}-\mathrm{g}$ lycosidic ribose-ribose bond or via phosphodiester bond formation between $\mathrm{C1}^{\prime}$ of ADP-ribose and the phosphate of a terminal nucleotide in a DNA duplex (Figure 2B).

More recently, it has been demonstrated that PARP2 and PARP3 covalently modify DNA termini in long linear and circular DNA duplexes by addition of ADP-ribose units to 5'-terminal phosphates (32) implying that PARPs-catalysed ADP-ribosylation may occur not only in short DNA fragments but also in genomic DNA. Importantly, under in vitro conditions PARPs can switch their substrate specificity from auto-ADP-ribosylation to DNA-ADP-ribosylation when using DNA substrates containing containing both DSB and SSB ends $(31,32)$. Noteworthy, histone PARylation factor 1 (HPF1, also referred as C4orf27), can modulate PARP1 activity via interaction with the CAT domain, enabling a switch from the cis mode of action (i.e. auto-ADP-ribosylation) to the trans mode (ADP-ribosylation of histones); this regulatory mechanism suppresses excessive PARP1 auto-PARylation upon genotoxic stress (35). Thus, the acceptor specificity of PARPs apparently depends on the nature of DNA substrate, interacting proteins and the chromatin domain context. DNA strand breaks prone to covalent modifications by PARPs can be generated either by direct action of reactive oxygen species, or during DNA replication, or by different DNA repair pathways when they process complex DNA damage. For example, nicks, gaps, and flaps mimic intermediates of the BER, NIR and other DNA excision repair pathways. DNA strand break termini containing 3'-phosphate groups can represent the products of action of bi-functional DNA glycosylases such as NEIL1 and NEIL2 on damaged bases, or of tyrosyl-DNA phosphodiesterase 1 (Tdp1) upon removal of a variety of covalent adducts from DNA (36).

At present, little is known about the mechanisms governing the acceptor site recognition and specificity of PARP1, which accounts for most of the cellular PARylation capacity. Protein PARylation activity of PARP1 was shown to be activated by different types of lesions and DNA structures including SSB, DSB, DNA crosslinks, stalled replication forks DNA hairpins, cruciforms, stably unpaired regions and other non-B-conformations of DNA (37), but it is unknown whether these DNA structures could be substrates for DNA ADPribosylation in vivo. A three-dimensional (3D) model of full-length PARP1 bound to dumbbell DNA with an SSB has been proposed based on the data coming from NMR, X-ray crystallography and mass spectrometry $(38,39)$. This model suggests that PARP1 bends a DNA duplex at the strand break through the cooperative action of two N-terminal zinc fingers ( $\mathrm{Zf1}$ and $\mathrm{Zf2}$ ) and then drives stepwise assembly of the remaining $\mathrm{Zf3}$ and WGR domains leading to unfolding of the autoinhibitory helical subdomain of the catalytic domain (CAT) and PARP1 activation. Molecular modelling revealed that the BRCT-WGR linker remains flexible and can reach the active site of PARP1, thus explaining the mechanism of auto-modification (in the cis mode) of this protein domain. However, this assembled PARP1/DNA structure still does not provide sufficient insight into the observed specificity in the trans mode for the nuclear protein acceptor sites and the substrate (DNA or protein) choice for ADP-ribosylation activity. Obviously, the substrate specificity of PARP1 could depend on the recruitment of the acceptor protein or DNA termini into close proximity to the CAT domain. Examination of the 3D structures and models of PARP1/DNA complexes reveals that the DNA-binding site of PARP1 in its active conformation is too far from its active site in the CAT domain $(38,40)$, implying that the DNA termini already occupied by PARP1 cannot be the acceptor sites for DNA PARylation. 


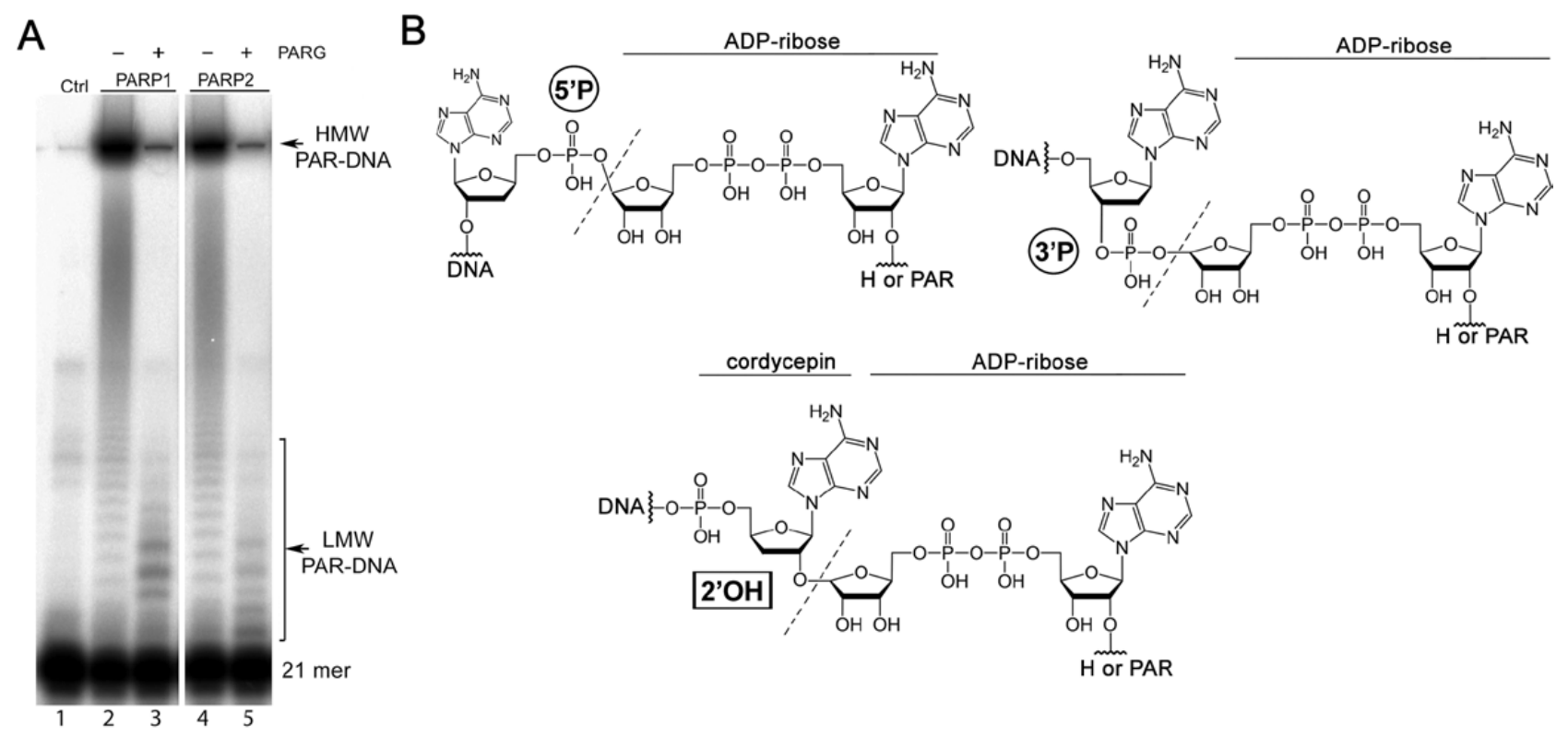

Figure 2. PARP1 and PARP2 covalently modify DNA strand break termini. (A) Denaturing gel electrophoresis of $5^{\prime 32}$-labeled oligonucleotide duplex incubated with PARPs and then with PARG. 'HMW' denotes high molecular weight PAR-DNA adducts, 'LMW' denotes low-molecular weight PAR-DNA adducts. (B) Chemical structures of DNA adducts generated by PARPs (cordycepin = 3'-deoxyadenosine). 'H' denotes hydrogen atom, 'PAR' denotes polymer of poly(ADP-ribose).

However, the second breakage site in the same DNA fragment, which is not bound by the protein, might interact with the CAT domain. Similarly, it was suggested that two molecules of PARP1 can ADPribosylate each other in trans when two binding sites are closely adjacent in the same DNA molecule, e.g., in a short duplex DNA containing two DSB ends (38). In the reports on PARP1,2 and 3-catalysed ADP-ribosylation of DNA, all oligonucleotide substrates had at least two DNA breakage sites; therefore, binding of a PARP molecule to one of them will activate the CAT domain, which could then target and ADP-ribosylate an acceptor group such as a $3^{\prime}$ - or 5'-terminal phosphate at the second breakage site of the same DNA molecule. Recently, Rudolph et al. proposed a model in which PARP1 scans chromosomal DNA by using a 'monkey bar' mechanism, in which the enzyme intermittently binds and releases DNA through Zf and WGR domains, always remaining attached to at least one binding site (41). We may speculate that when PARP1 binds to one DNA strand break using Zf1-Zf3 domains, the WGR domain searches for the second DNA binding site. When the WGR domain binds to another DNA strand break, it may bring the terminal DNA phosphate residues into close proximity to the activated CAT domain and enable DNA ADP-ribosylation.

Efficient ADP-ribosylation of duplex oligonucleotide fragments containing a DSB end and a single-stranded overhang by PARP1 suggest a possible role of modified DNA in DSB repair (31). Indeed, live cell imaging studies have shown that the accumulation of PARP1 and PAR at DSBs generated by laser-induced microirradiation occurs within $1 \mathrm{~s}$ after the DNA injury and is among the first events occurring at the sites of damage (42-44). PARP1 synthesises PAR that contributes to the rapid ATM-dependent DNA damage signalling by recruiting MRE11 and NBS1 to DSBs (42), as well as to stalled replication forks (45). The deposition of PAR at DSBs is likely involved in the efficient recruitment of ATM and MRE11, which both contain a functional PARbinding domain $(42,46,47)$. These observations strongly argue that PARP1 can efficiently compete with other DSB repair factors such as Ku70, RPA, 53BP1 and RAD51 for binding and repair of DNA strand breaks. PARP1-catalysed PARylation at 2'-OH of terminal cordycepin and ribonucleotide residues in DNA (31) points to a possible role of ADP-ribosylation in the repair of misincorporated ribonucleotides and other ribose-containing nucleoside analogues. Indeed, the presence of 2'-OH groups in DNA can be caused by ROS (48) and by misincoporation of ribonucleotides into DNA during DNA replication $(49,50)$. Furthermore, using in vitro biochemical assays, Munnur et al. demonstrated that human PARP family enzymes including PARP10, PARP11, PARP15 and a highly diverged PARP homologue, TRPT1, ADP-ribosylate phosphorylated ends of RNA, suggesting potential physiological relevance of this new nucleic acid modification (51). In conclusion, the studies of PARP-dependent modifications of DNA termini suggest that both the activation of PARPs and the accessibility of the DNA acceptor groups (terminal phosphates or hydroxyls) for the activated CAT domain of DNA-bound PARPs are necessary for the efficient DNA ADP-ribosylation.

The discovery of a new covalent modification of DNA mediated by PARPs provides novel molecular insights into many cellular functions of PARPs such as DNA repair, apoptosis, regulation of transcription and chromatin structure. For example, covalent modifications of DNA strand breaks may provide a plausible mechanism for the PARP-mediated inhibition of DNA replication and non-homologous end joining, and for the critical role of PARG in these processes (31). It can be reasonably assumed that the PARylated DNA termini in SSBs and DSBs (i) block replication by stimulating fork regression, possibly through interference with replicative DNA helicases, and prevent the mutagenic non-homologous end-joining via inhibition of Ku binding at double-strand DNA ends, respectively; (ii) initiate the stable assembly of DNA repair and chromatin remodelling machinery by the precise recruitment to the chromosome breakpoints; (iii) at the sites of clustered DNA damage, inhibit aberrant DNA repair and avoid the generation of DSBs. The time lapse before the removal of the PAR polymer from DNA by PARG could be used to recruit and assemble DNA repair machinery, which then would conduct the repair of clustered DNA damage in an orderly fashion. 
The highly efficient in vitro ADP-ribosylation of DNA strand break termini by the purified PARP proteins $(31,32,34)$ suggests that this type of DNA modification could also occur in vivo. At present, the majority of observations showing formation of PAR polymers in cells exposed to DNA damage do not distinguish PARylated proteins from poly- and mono-ADP-ribosylated DNA. Also, PARPs use the same active site for protein and DNA ADP-ribosylation, and presentday techniques are not sensitive enough to detect ADP-ribose-DNA adducts directly in the cell to address reliably the physiological relevance of this modification. Moreover, most of mutations in PARPs affecting their specificity to act on phosphate residues in DNA would also influence the auto- and protein ADP-ribosylation. The recent and future advances in technology, such as enzymatic labeling of terminal ADP-ribose residues (52) and development of specific antibodies against ADP-ribosylated DNA adducts, would certainly help to probe the physiological importance of covalent ADP-ribose DNA/ RNA modifications.

\section{Roles of PARP1 and DNA supercoiling in the chromatin organisation}

PARP homologues are present in species from all major eukaryotic kingdoms (53). It was demonstrated that PARPs are essential for embryonic development in a variety of multi-cellular organisms, including mice, Drosophila, and fungi (20,54-56). As noted above, the appearance of the PARP family proteins during the evolution of eukaryotes is possibly related to large sizes and chromatin organisation of their genomes. To fit their outsized genomes into the nucleus, eukaryotes package them in form of chromatin, a tight complex of DNA with histones and other proteins. The chromatin structure is central to the spatial organisation of the DNA helix because it balances the negatively charged DNA phosphates; it is also essential for gene regulation. Chromatin limits the access of transcriptional activators and repair factors to DNA. As a result, active mechanisms that alter the higher-order structure of chromatin to regulate DNA accessibility are required, such as ATP-dependent chromatin remodelling of nucleosomes, active DNA demethylation, and histone modifications including their PARylation. Indeed, the 3D chromatin architecture is highly dynamic and can be remodeled continuously when cells change their transcriptional programs and respond to environmental stimuli.

DNA strand breaks induced by laser microirradiation lead to a rapid ATP-dependent, ATM and $\gamma \mathrm{H} 2 \mathrm{AX}$-independent local decondensation of chromatin (57). Noteworthy, this process is sensitive to PARP inhibition and correlates with the displacement of $\mathrm{H} 1$ and core histones, indicating that PARylation is required to induce the transient chromatin opening (58). Thus, PAR serves to recruit and concentrate DNA repair and chromatin remodelling proteins at the lesion sites, at the same time loosening the chromatin to expose DNA to damage response proteins (59) and transcription factors (TFs) (60). Auto-PARylated PARP1 is able to sequester nucleosomes with high-efficiency in vitro, suggesting a possible histone chaperon function (61). Alternatively to the idea that PARP1-catalysed covalent PARylation of histones is required to open the chromatin structure, the chaperon model, previously described in (62), proposes noncovalent interactions of histones with PAR, which promote unfolding and displacement of nucleosomes from DNA. Thus, the PAR-induced rapid chromatin decondenstation at DNA damage sites may provide a mechanism for the PARP1-dependent transcription regulation.

In higher eukaryotes, the development and tissue-specific differentiation are driven by tightly coordinated gene expression patterns
$(63,64)$. Gene transcription starts when TFs bind to cis-regulatory sequences at promoters upstream of transcription start sites (TSSs) and initiate the assembly of the transcription preinitiation complex with RNA polymerase II (RNA PolII) $(65,66)$. Additional signals are often necessary for transcription through the gene bodies. As an additional level of control, gene expression is dependent on signals from distal cis-regulatory elements, including enhancers and insulators. Enhancers are often located in the non-coding regions of the genome and serve for spatial and temporal regulation of gene expression during the development and in a normal physiological state. Contrary to promoters, enhancers are activated in a cell typespecific manner $(67,68)$. Enhancers can operate even when located far away (hundreds to thousands kilobases) from their target genes (69). Large-scale chromatin decompaction observed in the inducible puffs in Drosophila polytene chromosomes reveals a new mechanism of chromatin reorganisation coupled to long-range gene activation by distant enhancer elements (70). Noteworthy, chromatin decompaction and gene activation at ecdysone and heat-shock induced puffs in Drosophila required both PARP1 and poly(ADPribosyl)ation (71,72). Furthermore, the large-scale chromatin unfolding observed between Sonic hedgehog locus and its brain enhancers in neural progenitor cells is mediated by the recruitment and activity of PARP1 (73). At present, little is known about the molecular mechanisms by which PARP1 promotes long-distance communication between enhancers and their target gene promoters.

One possible mechanism of chromatin decompaction is active DNA transcription. The elongating RNA polymerase unwinds the DNA duplex and generates positive supercoils ahead and negative ones behind. Positive DNA supercoiling promotes unwrapping of DNA from the nucleosomes in vitro, while nucleosomes rapidly form on negatively supercoiled DNA in the wake of transcription (74). The RNA polymerase generates one supercoil every ten base pairs, thus creating enormous torsional stress inhibitory for efficient transcription $(75,76)$. Topoisomerases relieve the torsional stress associated with transcription and replication by introducing transient nicks in DNA (77). In eukaryotes, transcription coupled to topoisomerase action is a major generator of negative supercoiling in the genome. Negative DNA supercoiling is required for the formation of an open promoter complex, transcription initiation, elongation and pausing $(78,79)$. In addition, chromatin remodelling complexes can generate negative supercoiling in DNA by nucleosome unwrapping. The superhelical state of cellular DNA can exist in two forms: a constrained state when DNA is wrapped around nucleosomes, and an unconstrained state, when the torsional stress is free to dissipate along the helix. In order to prevent the dissipation of supercoiling in the linear DNA molecule, the genome of an eukaryotic cell is organised into super-coiling domains with topological barriers. On the other hand, the spread of DNA supercoiling throughout the chromosome is not hindered by wrapping DNA around a nucleosome, and in vivo data suggest that supercoiling can be transmitted over several kilobases over large DNA supercoil domains $(80,81)$. Transcription activation leads to chromatin opening characterised by two features: spatial decompaction induced by changes in nucleosome-nucleosome interactions and linear decompaction due to changes in nucleosome density (82). In summary, DNA supercoiling induced by transcription or other factors can drive decompaction of large-scale chromatin domains prior to productive gene expression observed in the enhancer-mediated distant transcriptional regulation. 


\section{Molecular mechanism of PAR synthesis and} topological transitions in DNA

PARP1 binds to broken DNA strands through its multiple DNA binding domains and performs catalysis while holding DNA termini all the way during the synthesis of the PAR polymer. Electron microscope visualisation and atomic force microscopy of PAR reveals a dense tree-like structure with the number of branches increasing with the size of the PAR polymer (83). The branching points occur in a very regular manner with approximately 41 linear ADP-ribose residues between two branching $\left(2^{\prime \prime} \rightarrow 1^{\prime \prime \prime}\right)$ ribose-ribose linkage, thus reflecting the distance that allows the initiation of new synthesis (84). The narrow distribution of distances between the branching points is not consistent with spontaneous chain growth reinitiation at a random internal acceptor site but rather suggests a regularly repeated growth and reinitiation cycle. The co-crystal structure of catalytic domain of PARP1 with the inactive analogue carba-NAD revealed that the switch from elongation to branching reactions during PARylation occurs when the orientation of the bound polymer is reversed by a $180^{\circ}$ rotation of the active site cleft of the protein (85). Interestingly, biophysical studies showed that long-PAR chain may have a helical conformation (86) which may explain the reversal of orientation of polymer required for the branching. Atomic force microscopy data demonstrated a complex Christmas tree-like structure of the PAR polymer synthesised by PARP1 and PARP2, which remain bound to single- and double-strand DNA breaks (87). These data suggest that the length of the highly branched PAR polymer depends on the time of PARP1 and PARP2 residence on DNA. On the other side, the study of the diffusion of PARP1 on a DNA fragment containing an abasic site and a single-strand break in the presence of APE1, using combined atomic force and single molecule fluorescence microscopy, showed that auto-PARylation of PARP1 induces constrained and random one-dimensional motion along DNA which enables dissociation of the protein-DNA complex (88). Thus, it is tempting to speculate that the branched structure of PAR decreases the affinity of PARP1 for the lesion and allows the protein to move on DNA away from the lesion thus facilitating its hand-off to endcleansing repair enzymes, DNA ligase and DNA polymerase, which might be otherwise blocked by an immobile PARP1 molecule.

The unusual property of PARPs to catalyse long-branched PAR polymers may imply that the same enzyme molecule can switch from the terminal ADP-ribose residue in growing PAR chain to an internal one to initiate the branching synthesis without releasing the polymer. However, the importance of chain length and branching frequency of PAR for the cellular physiology and stress response remains unclear. A recent study demonstrated that the decrease in the PARP2-mediated branched PAR synthesis resulted in the significant delay of DSB repair in human cells (89). Furthermore, the expression of PARP1 mutant variants synthesising differently structured PAR in HeLa PARP1-KO cells revealed that PARP1-Y986S and PARP1G972R, variants producing short- and hypo-branched polymers, respectively, failed to rescue cells from genotoxic stress (90). Whereas, expression of PARP1-Y986H, a variant producing hyper-branched polymer, restored normal repair capacity of HeLa PARP1-KO cells, suggesting that the branching ratio is essential for the cellular stress response (90).

Of all PARP proteins, the structure of PARP1 is by far the best characterised. PARP1 consists of several sequential domains joined by flexible linkers. The identified domains include two homologous CCHC zinc fingers ( $\mathrm{Zf1}$ and $\mathrm{Zf2}$ ) characteristic of PARPs and DNA ligases, another $\mathrm{Zn}^{2+}$ and DNA-binding domain found in
poly(ADP-ribose)-synthetases (PADR1, sometimes called zinc finger 3 although by the secondary structure it is different from canonical zinc fingers), the BRCT domain, the WGR domain (named after the conserved central motif) also participating in DNA binding, and the catalytic domain (7,91-94). The catalytic domain itself consists of two subdomains, regulatory and ADP-ribosyltransferase (ART) $(95,96)$. The large size and the apparent conformational multiplicity of PARP1 has prevented the analysis of its structure as a whole, and it has been suggested, mainly from biochemical data, that free PARP1 exists as a rather flexible string of folded domains, which condenses into a more defined structure upon binding to damaged DNA $(38,39,97)$. Although, a large number of structures have been reported for the catalytic domain of PARP1 bound to various inhibitors $(85,95,98-112)$, much less is known about several other key domains of PARP1 and the overall organisation of the protein. NMR and crystal structures are available for isolated and DNAbound Zf1, Zf2 and their combination $(38,97,113,114)$ and PADR1 $(115,116)$. So far, the most complete PARP1 structure (hereafter referred to as maxPARP1) contains Zf1, PADR1, WGR, and catalytic domains bound to blunt ends of double-stranded DNA (40). In this structure, DNA binding is effected through Zf1, PADR1 and WGR domains, whereas the ART subdomain is the most distant from DNA and the regulatory domain is sandwiched between the DNAbinding elements and the ART subdomain (Figure 3A).

A comparison of the maxPARP1 structure that lacks $\mathrm{Zf2}$ and the structures containing one or both zinc fingers reveal several important features of DNA recognition by PARP1. First, binding to a dsDNA blunt end, as in maxPARP1, and to a nick in dsDNA, can be achieved in a very similar structural manner, with a sharp kink in the nicked DNA (Figure 3B). Second, Zf1 and Zf2 individually can stack against the terminal DNA bases and grip phosphates near the terminus, and when both fingers are present, they assume equivalent positions at the sides of a nick (Figure $3 \mathrm{~B}$ and $\mathrm{C}$ ) but compete for a blunt end, which can be capped by either Zf1 or Zf2 (Figure 3A and C). With this flexibility, it is likely that PARP1 can accommodate a wide range of axial DNA rotation when bound to a dsDNA end but is fixed tighter on a nick.

Binding of damaged DNA activates the catalytic function of PARP1. Normally, the regulatory domain folds over the NAD+binding pocket of the ADP-ribosyltransferase domain and inhibits the activity; to relieve the autoinhibition, the regulatory domain has to be unfolded (39). In the structure of DNA-bound maxPARP1, the regulatory subdomain is locally rearranged and rotated by $\sim 10^{\circ}$ relative to the structure of an isolated catalytic fragment, partly opening the entrance to the catalytic pocket of the ART subdomain (40). This may reflect only the initial stages of unfolding, since hydrogen-deuterium exchange data are indicative of a much more pronounced regulatory subdomain melting (39). As a result, in the fully activated PARP1 the catalytic domain should move even farther from DNA and should be less restricted in the orientation and distance of reach for the PARylation targets.

Upon target binding, the first (ADP-ribosyl)ation event is ratelimiting, and the PAR chain grows fast thereafter, suggesting the enzyme works in a processive manner (117). Addition of an ADP-ribose unit at the distal end of a growing PAR chain increases its length by $\sim 10 \AA$, the distance between $\mathrm{C1}^{\prime}$ atoms of the two ribose moieties in $\mathrm{NAD}^{+}$. How this elongation is accommodated in the structure is a question critical for understanding the movement of PARPs and their interaction partners. Molecular dynamics modelling of linear and branched PAR chains suggests that their shape is mostly driven by geometry constraints, with only a limited number of irregular hydrogen bonds stabilising the 


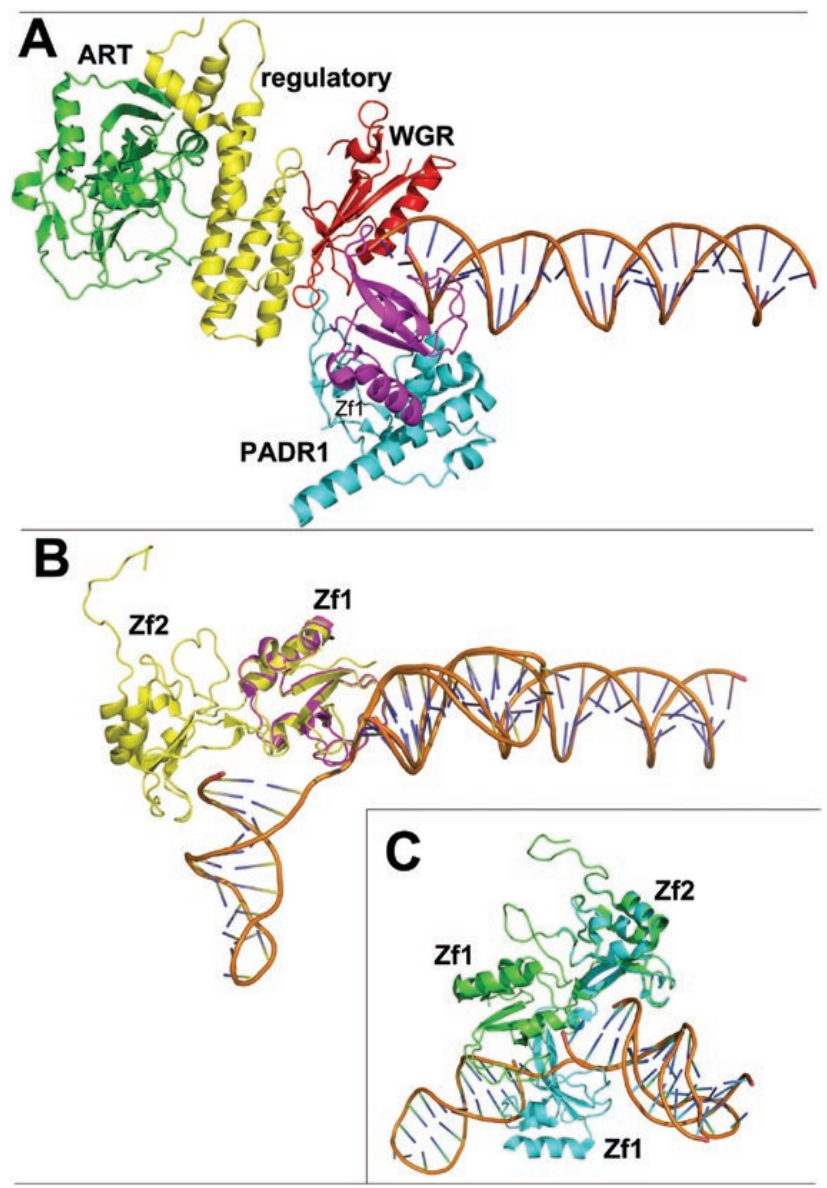

Figure 3. Structure of PARP1 bound to DNA. (A) maxPARP1 structure (PDB ID 4DQY (40)). Protein domains are color-coded: magenta, Zf1, cyan, PADR1, red, WGR, yellow, regulatory subdomain; green, ART subdomain. (B) Overlay of $Z f 1$ (magenta) from maxPARP1 and $Z f 1$ and $Z f 2$ (yellow) from the structure of the N-terminal part of PARP1 bound to dumbbell nicked DNA (2N8A (38)); $\mathrm{Zf1}$ domains superimposed. Note the sharp kink in the dumbbell nicked DNA and the same orientation of Zf1 on DNA in both structures. (C) Overlay of $\mathrm{Zf1}$ and $\mathrm{Zf2}$ from the structure of the $\mathrm{N}$-terminal part of PARP1 bound to dumbbell nicked DNA (2N8A, green) and to the ends of linear DNA (4AV1 (114), cyan); Zf2 domains superimposed. Note that Zf1 assumes a different position relative to DNA in $4 \mathrm{AV} 1$ compared with $2 \mathrm{~N} 8 \mathrm{~A}$ and $4 \mathrm{DQY}$.

structure (118). The increasing length of the PAR chain will inevitably pull the PARP molecule and the PARylated molecule apart. However, if PARP is tightly bound to a DNA nick, its translational motion would necessitate an accompanying movement of the DNA stretch, which is energetically unfavourable due to the solvent viscosity at the molecular scale (Figure 4A). Given that the translational diffusion coefficient is inversely proportional to the apparent hydrodynamic radius $(r)$ whereas the rotational diffusion coefficient is inversely proportional to $r^{3}$, rotational thermal movement is predominant at the protein- or DNA-size scale, especially in crowded environments (119-121). For elongated molecules such as DNA, the axial rotation is even more favourable compared with transverse linear movement or lateral rotation $(122,123)$.

Based on the structural and biochemical observations, we put forward the following model of PARPs action integrating PAR synthesis and DNA topology (Figure 4B). The growing PAR chain attached to a target (a DNA terminus or a protein bound to DNA) causes angular displacement of the PARP molecule. Essentially, PARP shoves off the target, which would be especially efficient if the target

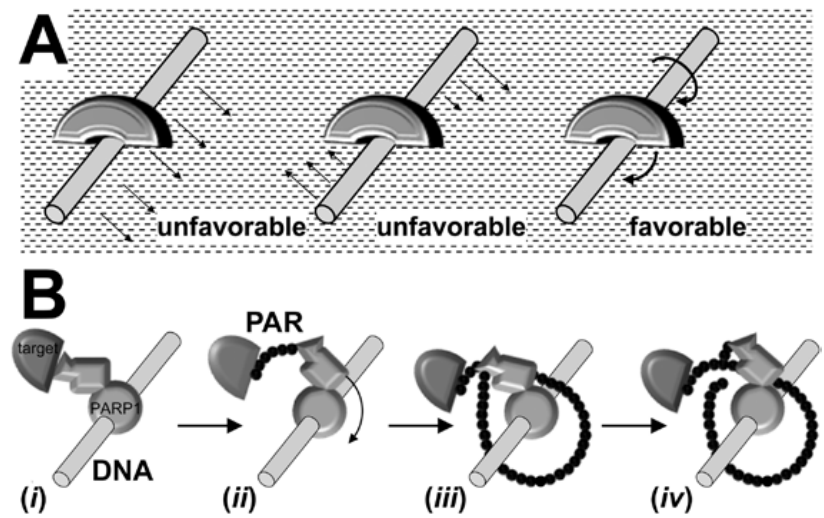

Figure 4. (A) Scheme of translational and rotational motions of nanoscale structures in viscous liquid. DNA is shown as a rod, and a bound protein, as a half-torus shape. (B) Proposed model of PARP rotation on DNA causing PAR chain branching. PARP1 sits on a DNA break and tightly holds the ends, while the activated CAT domain interacts with the target (i). Adding monomers to a growing PAR chain pushes the PARP1 molecule, which rotates around the DNA axis while still holding the break termini (ii). Ultimately, PARP1 makes a full turn and comes back to an earlier-synthesised PAR stretch (iii) where it can switch to an internal acceptor moiety generating a branchpoint (iv).

is restricted in its mobility due to interactions with other proteins or DNA in the nucleus. Eventually, PARP makes a full turn around DNA and encounters the PAR chain 40 monomeric units back from the growing end (the distance may be different near the double-strand break, which allows a shorter rotation radius). At this time, an internal ADP-ribose monomer can find its way into the active site of PARP1 and present its 2'-hydroxyl as an ADP-ribose acceptor, resulting in the formation of the branched polymer. Moreover, in the process of this circular PARylation PARPs may also switch to the free 2'-OH group of the ADP-ribose at the end of another PAR branch, thus generating complex tree-like structures. Tightly gripping one DNA strand near the break with the zinc fingers, PARPs can change the duplex helicity during rotation using the energy of the polymerisation reaction.

The association of branched PAR synthesis and topological transitions in DNA could shed new light on the biological function of the PARP-catalysed PARylation in DNA strand-break repair and transcription regulation. Indeed, PARPs-catalysed changes in DNA duplex topology, possibly the formation of positive supercoils, could explain chromatin decondensation without release of PARylated histones from DNA (124). Introduction of DNA strand breaks causes relaxation of supercoiled DNA, which in turn provokes long-distance conformational changes in chromatin, affecting transcription machinery and TFs binding to DNA far away from the break. Rapid recruitment of PARPs to DNA strand breaks and subsequent PARylation may be required to revert DNA to the supercoiled state and to remodel the surrounding chromatin for easier access of DNA repair proteins. Recruitment of PARPs to specific regulatory DNA sequences and to non-B-DNA conformations and subsequent DNA-dependent PARylation may induce either negative or positive supercoiling, and thus have different effects on DNA transcription regulation. Further studies are needed to examine the topology-modulating activity of PARP enzymes.

\section{Conclusions}

Here, we have reviewed the roles of PARP-catalysed ADPribosylation of proteins and nucleic acids in DNA damage 
signalling, DNA repair and chromatin organisation. Analysis of the mechanism of ADP-ribosylation of DNA strand break termini and the role of PARP1 in transcription regulation lead us to hypothesise that PARP1 may prevent the strand break-dependent loss of DNA superhelical state by introducing positive supercoils. The torsional stress in DNA created by the PAR synthesis would lead to nucleosomes displacement and chromatin decompaction starting from the DNA lesion site and enable the recruitment of DNA repair machinery. Recruitment of PARP1 and activation of PARylation at regulatory DNA regions such as enhancers may enable large-scale chromatin decompaction and interaction with promoter followed by transcription activation. Thus, PARP1-catalysed PARylation may play a role similar to transcription to activate distal promoters via DNA topology-dependent induction of long-distance chromatin changes. Although speculative, the model described here reconciles a number of unresolved issues in PARP biology, and, most importantly, provides new experimental lines to address the biological role of ADP-ribosylation. Testable predictions from the model are, e.g., that the branched structure of PAR polymer should be essential for the biological functions of PARP1, and that the level of DNA supercoiling in living cells should depend on the presence of active PARP1 and PARP2.

To summarise our vision of PARP, below we highlight several key points:

- The presence of multiple strand breaks within one DNA fragment or a specific interacting partner can switch mode of action of PARPs from cis (auto-ADP-ribosylation) to trans (either DNA or protein ADP-ribosylation, respectively);

- PARP1 catalyses processive synthesis of a long-polymer with regular branching points, suggesting that PAR may have a helical structure and that PARP1 moves around DNA while catalysing elongation synthesis of 40 -mer linear PAR polymer before switching to the branching synthesis by using a 2'-OH group of an internal ADPribose unit;

- Rotation of PARP1 around DNA is the easiest way to accommodate PAR chain elongation in the viscous and crowded environment;

- Rotation of PARP1 tightly bound to an end of the DNA strand break can introduce either negative or positive supercoils in the DNA helix. Introduction of positive supercoils in DNA helix by PARP1 would lead to nucleosome displacement and remodelling, which in turn would result in chromatin decompaction;

- PARP1 acts in a similar manner to RNA polymerase to introduce positive supercoils propagating along the DNA helix, drawing energy from the hydrolysis of monomers during the synthesis of PAR and RNA polymers, respectively;

- PARylation-induced positive DNA supercoiling may be the primary cause of PARP1-dependent long-range gene activation by enhancer elements associated with a large-scale decompaction of chromatin in the DNA regions between enhancers and promoters.

\section{Acknowledgements}

We would like to thank Drs Jacques Laval and Alexander Ishchenko for fruitful discussion.

\section{Funding}

This work was supported by grants to Murat Saparbaev from la Ligue National Contre le Cancer 'Equipe Labellisee', Electricité de France (RB 2017) and French National Center for Scientific Research (PRC CNRS/RFBR n1074 REDOBER); and to Bakhyt T. Matkarimov from Nazarbayev University Oak Ridge Associated Universities (ORAU) grant 091019CRP2111 and Ministry of Education and Science of the Republic of Kazakhstan grants AP05133910, AP05134683 program BR05236508; and to Dmitry O. Zharkov from the Russian Ministry of Science and Education (6.5773.2017/6.7 and AAAA-A17-117020210023-1) and Russian Foundation for Basic Research (17-00-00261). The funders had no role in study design, data collection and analysis, decision to publish, or preparation of the manuscript.

Conflict of interest statement: None declared.

\section{References.}

1. Cadet, J. and Wagner, J. R. (2013) DNA base damage by reactive oxygen species, oxidizing agents, and UV radiation. Cold Spring Harbor Perspect Biol, 5, a012559.

2. Balasubramanian, B., Pogozelski, W. K. and Tullius, T. D. (1998) DNA strand breaking by the hydroxyl radical is governed by the accessible surface areas of the hydrogen atoms of the DNA backbone. Proc. Natl. Acad. Sci. U. S. A., 95, 9738-9743.

3. Pommier, Y., Leo, E., Zhang, H. and Marchand, C. (2010) DNA topoisomerases and their poisoning by anticancer and antibacterial drugs. Chem. Biol., 17, 421-433.

4. Schreiber, V., Dantzer, F., Ame, J. C. and de Murcia, G. (2006) Poly(ADPribose): novel functions for an old molecule. Nat. Rev. Mol. Cell Biol., 7, 517-528.

5. Kim, M. Y., Zhang, T. and Kraus, W. L. (2005) Poly(ADP-ribosyl)ation by PARP-1: 'PAR-laying' NAD+ into a nuclear signal. Genes Dev., 19, 1951-1967.

6. Hottiger, M. O., Hassa, P. O., Lüscher, B., Schüler, H. and KochNolte, F. (2010) Toward a unified nomenclature for mammalian ADPribosyltransferases. Trends Biochem. Sci., 35, 208-219.

7. de Murcia, G. and Ménissier de Murcia, J. (1994) Poly(ADP-ribose) polymerase: a molecular nick-sensor. Trends Biochem. Sci., 19, 172-176.

8. Tanaka, Y., Yoshihara, K., Itaya, A., Kamiya, T. and Koide, S. S. (1984) Mechanism of the inhibition of $\mathrm{Ca}^{2+}, \mathrm{Mg}^{2+}$-dependent endonuclease of bull seminal plasma induced by ADP-ribosylation. J. Biol. Chem., 259, 6579-6585.

9. Satoh, M. S., Poirier, G. G. and Lindahl, T. (1994) Dual function for poly(ADP-ribose) synthesis in response to DNA strand breakage. Biochemistry, 33, 7099-7106.

10. Koh, D. W., Lawler, A. M., Poitras, M. F., et al. (2004) Failure to degrade poly(ADP-ribose) causes increased sensitivity to cytotoxicity and early embryonic lethality. Proc. Natl. Acad. Sci. U. S. A., 101, 17699-17704.

11. Amé, J. C., Fouquerel, E., Gauthier, L. R., Biard, D., Boussin, F. D., Dantzer, F., de Murcia, G. and Schreiber, V. (2009) Radiation-induced mitotic catastrophe in PARG-deficient cells. J. Cell Sci., 122, 1990-2002.

12. Fisher, A. E., Hochegger, H., Takeda, S. and Caldecott, K. W. (2007) Poly(ADP-ribose) polymerase 1 accelerates single-strand break repair in concert with poly(ADP-ribose) glycohydrolase. Mol. Cell. Biol., 27, 5597-5605.

13. Tang, J. B., Svilar, D., Trivedi, R. N., et al. (2011) N-methylpurine DNA glycosylase and DNA polymerase beta modulate BER inhibitor potentiation of glioma cells to temozolomide. Neuro. Oncol., 13, 471-486.

14. Langelier, M. F. and Pascal, J. M. (2013) PARP-1 mechanism for coupling DNA damage detection to poly(ADP-ribose) synthesis. Curr. Opin. Struct. Biol., 23, 134-143.

15. Amé, J. C., Rolli, V., Schreiber, V., et al. (1999) PARP-2, A novel mammalian DNA damage-dependent poly(ADP-ribose) polymerase. J. Biol. Chem., 274, 17860-17868.

16. Kutuzov, M. M., Khodyreva, S. N., Amé, J. C., Ilina, E. S., Sukhanova, M. V., Schreiber, V. and Lavrik, O. I. (2013) Interaction of PARP-2 with DNA 
structures mimicking DNA repair intermediates and consequences on activity of base excision repair proteins. Biochimie, 95, 1208-1215.

17. Saparbaev, M. K. and Zharkov, D. O. (2017) Glycosylase repair. Reference Module in Life Sciences. Elsevier, Amsterdam, The Netherlands.

18. Ischenko, A. A. and Saparbaev, M. K. (2002) Alternative nucleotide incision repair pathway for oxidative DNA damage. Nature, 415, 183-187.

19. de Murcia, J. M., Niedergang, C., Trucco, C., et al. (1997) Requirement of poly(ADP-ribose) polymerase in recovery from DNA damage in mice and in cells. Proc. Natl. Acad. Sci. U. S. A., 94, 7303-7307.

20. Menissier de Murcia, J., Ricoul, M., Tartier, L., et al. (2003) Functional interaction between PARP-1 and PARP-2 in chromosome stability and embryonic development in mouse. Embo J., 22, 2255-2263.

21. Molinete, M., Vermeulen, W., Bürkle, A., Ménissier-de Murcia, J., Küpper, J. H., Hoeijmakers, J. H. and de Murcia, G. (1993) Overproduction of the poly(ADP-ribose) polymerase DNA-binding domain blocks alkylation-induced DNA repair synthesis in mammalian cells. EMBO J., 12, 2109-2117.

22. Murai, J., Huang, S. Y., Das, B. B., Renaud, A., Zhang, Y., Doroshow, J. H., Ji, J., Takeda, S. and Pommier, Y. (2012) Trapping of PARP1 and PARP2 by Clinical PARP Inhibitors. Cancer Res., 72, 5588-5599.

23. El-Khamisy, S. F., Masutani, M., Suzuki, H. and Caldecott, K. W. (2003) A requirement for PARP-1 for the assembly or stability of XRCC1 nuclear foci at sites of oxidative DNA damage. Nucleic Acids Res., 31, 5526- 5533

24. Nazarkina, Z. K., Khodyreva, S. N., Marsin, S., Lavrik, O. I. and Radicella, J. P. (2007) XRCC1 interactions with base excision repair DNA intermediates. DNA Repair (Amst)., 6, 254-264.

25. Caldecott, K. W. (2014) Protein ADP-ribosylation and the cellular response to DNA strand breaks. DNA Repair (Amst)., 19, 108-113.

26. Luger, K. and Hansen, J. C. (2005) Nucleosome and chromatin fiber dynamics. Curr. Opin. Struct. Biol., 15, 188-196.

27. Hinz, J. M., Rodriguez, Y. and Smerdon, M. J. (2010) Rotational dynamics of DNA on the nucleosome surface markedly impact accessibility to a DNA repair enzyme. Proc. Natl. Acad. Sci. U. S. A., 107, 4646-4651.

28. Odell, I. D., Barbour, J. E., Murphy, D. L., Della-Maria, J. A., Sweasy, J. B., Tomkinson, A. E., Wallace, S. S. and Pederson, D. S. (2011) Nucleosome disruption by DNA ligase III-XRCC1 promotes efficient base excision repair. Mol. Cell. Biol., 31, 4623-4632.

29. Kraus, W. L. and Hottiger, M. O. (2013) PARP-1 and gene regulation: progress and puzzles. Mol. Aspects Med., 34, 1109-1123.

30. Caldecott, K. W. (2007) Mammalian single-strand break repair: mechanisms and links with chromatin. DNA Repair (Amst)., 6, 443-453.

31. Talhaoui, I., Lebedeva, N. A., Zarkovic, G., et al. (2016) Poly(ADP-ribose) polymerases covalently modify strand break termini in DNA fragments in vitro. Nucleic Acids Res., 44, 9279-9295.

32. Zarkovic, G., Belousova, E. A., Talhaoui, I., et al. (2018) Characterization of DNA ADP-ribosyltransferase activities of PARP2 and PARP3: new insights into DNA ADP-ribosylation. Nucleic Acids Res., 46, 2417-2431.

33. Munnur, D. and Ahel, I. (2017) Reversible mono-ADP-ribosylation of DNA breaks. FEBS J., 284, 4002-4016.

34. Belousova, E. A., Ishchenko, A. A. and Lavrik, O. I. (2018) DNA is a new target of PARP3. Sci. Rep., 8, 4176.

35. Gibbs-Seymour, I., Fontana, P., Rack, J. G. M. and Ahel, I. (2016) HPF1/ C4orf27 Is a PARP-1-interacting protein that regulates PARP-1 ADPribosylation activity. Mol. Cell, 62, 432-442.

36. Lebedeva, N. A., Rechkunova, N. I., Ishchenko, A. A., Saparbaev, M. and Lavrik, O. I. (2013) The mechanism of human tyrosyl-DNA phosphodiesterase 1 in the cleavage of AP site and its synthetic analogs. DNA Repair (Amst)., 12, 1037-1042.

37. Lonskaya, I., Potaman, V. N., Shlyakhtenko, L. S., Oussatcheva, E. A., Lyubchenko, Y. L. and Soldatenkov, V. A. (2005) Regulation of poly(ADPribose) polymerase-1 by DNA structure-specific binding. J. Biol. Chem., 280, 17076-17083.

38. Eustermann, S., Wu, W. F., Langelier, M. F., Yang, J. C., Easton, L. E., Riccio, A. A., Pascal, J. M. and Neuhaus, D. (2015) Structural basis of detection and signaling of DNA single-strand breaks by human PARP-1. Mol. Cell, 60, 742-754.
39. Dawicki-McKenna, J. M., Langelier, M. F., DeNizio, J. E., et al. (2015) PARP-1 activation requires local unfolding of an autoinhibitory domain. Mol. Cell, 60, 755-768.

40. Langelier, M. F., Planck, J. L., Roy, S. and Pascal, J. M. (2012) Structural basis for DNA damage-dependent poly(ADP-ribosyl)ation by human PARP-1. Science, 336, 728-732.

41. Rudolph, J., Mahadevan, J., Dyer, P., and Luger, K. (2018) Poly(ADPribose) polymerase 1 searches DNA via a 'monkey bar' mechanism. Elife, 7, e37818, 1-23.

42. Haince, J. F., McDonald, D., Rodrigue, A., Déry, U., Masson, J. Y., Hendzel, M. J. and Poirier, G. G. (2008) PARP1-dependent kinetics of recruitment of MRE11 and NBS1 proteins to multiple DNA damage sites. J. Biol. Chem., 283, 1197-1208.

43. Mortusewicz, O., Amé, J. C., Schreiber, V. and Leonhardt, H. (2007) Feedback-regulated poly(ADP-ribosyl)ation by PARP-1 is required for rapid response to DNA damage in living cells. Nucleic Acids Res., 35, $7665-7675$

44. Mahadevan, J., Rudolph, J., Jha, A., Tay, J. W., Dragavon, J., Grumstrup, E. M. and Luger, K. (2019) Q-FADD: a mechanistic approach for modeling the accumulation of proteins at sites of DNA damage. Biophys. J., 116, 2224-2233.

45. Bryant, H. E., Petermann, E., Schultz, N., et al. (2009) PARP is activated at stalled forks to mediate Mre11-dependent replication restart and recombination. EMBO J., 28, 2601-2615.

46. Haince, J. F., Kozlov, S., Dawson, V. L., Dawson, T. M., Hendzel, M. J., Lavin, M. F. and Poirier, G. G. (2007) Ataxia telangiectasia mutated (ATM) signaling network is modulated by a novel poly(ADP-ribose)-dependent pathway in the early response to DNA-damaging agents. J. Biol. Chem., 282, 16441-16453.

47. Aguilar-Quesada, R., Muñoz-Gámez, J. A., Martín-Oliva, D., et al. (2007) Interaction between ATM and PARP-1 in response to DNA damage and sensitization of ATM deficient cells through PARP inhibition. BMC Mol. Biol., 8, 29 .

48. Schuchmann, M. N., Steenken, S., Wroblewski, J. and von Sonntag, C. (1984) Site of OH radical attack on dihydrouracil and some of its methyl derivatives. Int. J. Radiat. Biol. Relat. Stud. Phys. Chem. Med., 46, 225-232.

49. Joyce, C. M. (1997) Choosing the right sugar: how polymerases select a nucleotide substrate. Proc. Natl. Acad. Sci. U. S. A., 94, 1619-1622.

50. Clausen, A. R., Zhang, S., Burgers, P. M., Lee, M. Y. and Kunkel, T. A. (2013) Ribonucleotide incorporation, proofreading and bypass by human DNA polymerase $\delta$. DNA Repair (Amst)., 12, 121-127.

51. Munnur, D., Bartlett, E., Mikolčević, P., Kirby, I. T., Matthias Rack, J. G., Mikoč, A., Cohen, M. S. and Ahel, I. (2019) Reversible ADP-ribosylation of RNA. Nucleic Acids Res., 47, 5658-5669.

52. Ando, Y., Elkayam, E., McPherson, R. L., et al. (2019) ELTA: enzymatic labeling of terminal ADP-Ribose. Mol. Cell, 73, 845-856.e5.

53. Perina, D., Mikoč, A., Ahel, J., Ćetković, H., Žaja, R. and Ahel, I. (2014) Distribution of protein poly(ADP-ribosyl)ation systems across all domains of life. DNA Repair (Amst)., 23, 4-16.

54. Tulin, A., Stewart, D. and Spradling, A. C. (2002) The Drosophila heterochromatic gene encoding poly(ADP-ribose) polymerase (PARP) is required to modulate chromatin structure during development. Genes Dev., 16, 2108-2119.

55. Semighini, C. P., Savoldi, M., Goldman, G. H. and Harris, S. D. (2006) Functional characterization of the putative Aspergillus nidulans poly(ADPribose) polymerase homolog PrpA. Genetics, 173, 87-98.

56. Jubin, T., Kadam, A. and Begum, R. (2019) Poly(ADP-ribose) polymerase-1 (PARP-1) regulates developmental morphogenesis and chemotaxis in Dictyostelium discoideum. Biol. Cell, 111, 187-197.

57. Kruhlak, M. J., Celeste, A., Dellaire, G., Fernandez-Capetillo, O., Müller, W. G., McNally, J. G., Bazett-Jones, D. P. and Nussenzweig, A. (2006) Changes in chromatin structure and mobility in living cells at sites of DNA double-strand breaks. J. Cell Biol., 172, 823-834.

58. Strickfaden, H., McDonald, D., Kruhlak, M. J., et al. (2016) Poly(ADPribosyl)ation-dependent transient chromatin decondensation and histone displacement following laser microirradiation. J. Biol. Chem., 291, 17891802. 
59. Smith, R., Lebeaupin, T., Juhasz, S., et al. (2019) Poly(ADP-ribose)dependent chromatin unfolding facilitates the association of DNA-binding proteins with DNA at sites of damage. Nucleic Acids Res., pii: gkz820. https://oi.org/10.1093/nar/gkz820 [Epub ahead of print]

60. Izhar, L., Adamson, B., Ciccia, A., et al. (2015) A systematic analysis of factors localized to damaged chromatin reveals parp-dependent recruitment of transcription factors. Cell Rep., 11, 1486-1500.

61. Muthurajan, U. M., Hepler, M. R., Hieb, A. R., Clark, N. J., Kramer, M., Yao, T. and Luger, K. (2014) Automodification switches PARP-1 function from chromatin architectural protein to histone chaperone. Proc. Natl. Acad. Sci. U. S. A., 111, 12752-12757.

62. Althaus, F. R., Höfferer, L., Kleczkowska, H. E., Malanga, M., Naegeli, H., Panzeter, P. L. and Realini, C. A. (1994) Histone shuttling by poly ADPribosylation. Mol. Cell. Biochem., 138, 53-59.

63. Andersson, R., Gebhard, C., Miguel-Escalada, I., et al. (2014) An atlas of active enhancers across human cell types and tissues. Nature, 507, 455- 461.

64. Chazaud, C. and Yamanaka, Y. (2016) Lineage specification in the mouse preimplantation embryo. Development, 143, 1063-1074.

65. Andersson, R., Sandelin, A. and Danko, C. G. (2015) A unified architecture of transcriptional regulatory elements. Trends Genet., 31, 426-433.

66. Osório, J. (2016) Gene regulation: landscape and mechanisms of transcription factor cooperativity. Nat. Rev. Genet., 17, 5.

67. Visel, A., Blow, M. J., Li, Z., et al. (2009) ChIP-seq accurately predicts tissue-specific activity of enhancers. Nature, 457, 854-858.

68. Thurman, R. E., Rynes, E., Humbert, R., et al. (2012) The accessible chromatin landscape of the human genome. Nature, 489, 75-82.

69. Vernimmen, D. and Bickmore, W. A. (2015) The hierarchy of transcriptional activation: from enhancer to promoter. Trends Genet., 31, 696-708.

70. Fukaya, T., Lim, B. and Levine, M. (2016) Enhancer control of transcriptional bursting. Cell, 166, 358-368.

71. Sawatsubashi, S., Maki, A., Ito, S., et al. (2004) Ecdysone receptordependent gene regulation mediates histone poly(ADP-ribosyl)ation. Biochem. Biophys. Res. Commun., 320, 268-272.

72. Tulin, A. and Spradling, A. (2003) Chromatin loosening by poly(ADP)ribose polymerase (PARP) at Drosophila puff loci. Science, 299, 560-562.

73. Benabdallah, N. S., Williamson, I., Illingworth, R. S., Boyle, S., Grimes, G. R., Therizols, P., and Bickmore, W. A. (2017) PARP mediated chromatin unfolding is coupled to long-range enhancer activation. bioRxiv, 155325.

74. Freeman, L. A. and Garrard, W. T. (1992) DNA supercoiling in chromatin structure and gene expression. Crit. Rev. Eukaryot. Gene Expr., 2, 165- 209.

75. Liu, L. F. and Wang, J. C. (1987) Supercoiling of the DNA template during transcription. Proc. Natl. Acad. Sci. U. S. A., 84, 7024-7027.

76. Joshi, R. S., Piña, B. and Roca, J. (2010) Positional dependence of transcriptional inhibition by DNA torsional stress in yeast chromosomes. EMBO J., 29, 740-748.

77. Wang, J. C. (2002) Cellular roles of DNA topoisomerases: a molecular perspective. Nat. Rev. Mol. Cell Biol., 3, 430-440.

78. Ma, J., Bai, L. and Wang, M. D. (2013) Transcription under torsion. Science, 340, 1580-1583.

79. Dunaway, M. and Ostrander, E. A. (1993) Local domains of supercoiling activate a eukaryotic promoter in vivo. Nature, 361, 746-748.

80. Kouzine, F., Sanford, S., Elisha-Feil, Z. and Levens, D. (2008) The functional response of upstream DNA to dynamic supercoiling in vivo. Nat. Struct. Mol. Biol., 15, 146-154.

81. Naughton, C., Avlonitis, N., Corless, S., et al. (2013) Transcription forms and remodels supercoiling domains unfolding large-scale chromatin structures. Nat. Struct. Mol. Biol., 20, 387-395.

82. Even-Faitelson, L., Hassan-Zadeh, V., Baghestani, Z. and BazettJones, D. P. (2016) Coming to terms with chromatin structure. Chromosoma, 125, 95-110.

83. de Murcia, G., Jongstra-Bilen, J., Ittel, M. E., Mandel, P. and Delain, E. (1983) Poly(ADP-ribose) polymerase auto-modification and interaction with DNA: electron microscopic visualization. EMBO J., 2, 543-548.
84. Keith, G., Desgrès, J. and de Murcia, G. (1990) Use of two-dimensional thin-layer chromatography for the components study of poly(adenosine diphosphate ribose). Anal. Biochem., 191, 309-313.

85. Ruf, A., Rolli, V., de Murcia, G. and Schulz, G. E. (1998) The mechanism of the elongation and branching reaction of poly(ADP-ribose) polymerase as derived from crystal structures and mutagenesis. J. Mol. Biol., 278, $57-65$.

86. Minaga, T. and Kun, E. (1983) Probable helical conformation of poly(ADP-ribose). The effect of cations on spectral properties. J. Biol. Chem., 258, 5726-5730.

87. Sukhanova, M. V., Abrakhi, S., Joshi, V., Pastre, D., Kutuzov, M. M., Anarbaev, R. O., Curmi, P. A., Hamon, L. and Lavrik, O. I. (2016) Single molecule detection of PARP1 and PARP2 interaction with DNA strand breaks and their poly(ADP-ribosyl)ation using high-resolution AFM imaging. Nucleic Acids Res., 44, e60.

88. Liu, L., Kong, M., Gassman, N. R., Freudenthal, B. D., Prasad, R., Zhen, S., Watkins, S. C., Wilson, S. H. and Van Houten, B. (2017) PARP1 changes from three-dimensional DNA damage searching to one-dimensional diffusion after auto-PARylation or in the presence of APE1. Nucleic Acids Res., $45,12834-12847$

89. Chen, Q., Kassab, M. A., Dantzer, F. and Yu, X. (2018) PARP2 mediates branched poly ADP-ribosylation in response to DNA damage. Nat. Commun., 9, 3233.

90. Rank, L. (2019) Cellular characterization of PARP1 variants with altered enzymatic activities. Dissertation. Universität Konstanz, Konstanz.

91. Bork, P., Hofmann, K., Bucher, P., Neuwald, A. F., Altschul, S. F. and Koonin, E. V. (1997) A superfamily of conserved domains in DNA damage-responsive cell cycle checkpoint proteins. FASEB J., 11, 68-76.

92. Huyton, T., Bates, P. A., Zhang, X., Sternberg, M. J. and Freemont, P. S. (2000) The BRCA1 C-terminal domain: structure and function. Mutat. Res., 460, 319-332.

93. Staub, E., Fiziev, P., Rosenthal, A. and Hinzmann, B. (2004) Insights into the evolution of the nucleolus by an analysis of its protein domain repertoire. Bioessays, 26, 567-581.

94. Hassa, P. O., Covic, M., Bedford, M. T. and Hottiger, M. O. (2008) Protein arginine methyltransferase 1 coactivates NF-kappaB-dependent gene expression synergistically with CARM1 and PARP1. J. Mol. Biol., 377, 668678.

95. Ruf, A., Mennissier de Murcia, J., de Murcia, G. and Schulz, G. E. (1996) Structure of the catalytic fragment of poly(AD-ribose) polymerase from chicken. Proc. Natl. Acad. Sci. U. S. A., 93, 7481-7485.

96. Smith, S. (2001) The world according to PARP. Trends Biochem. Sci., 26, 174-179.

97. Eustermann, S., Videler, H., Yang, J. C., Cole, P. T., Gruszka, D., Veprintsev, D. and Neuhaus, D. (2011) The DNA-binding domain of human PARP-1 interacts with DNA single-strand breaks as a monomer through its second zinc finger. J. Mol. Biol., 407, 149-170.

98. Ruf, A., de Murcia, G. and Schulz, G. E. (1998) Inhibitor and NAD+ binding to poly(ADP-ribose) polymerase as derived from crystal structures and homology modeling. Biochemistry, 37, 3893-3900.

99. White, A. W., Almassy, R., Calvert, A. H., et al. (2000) Resistancemodifying agents. 9. Synthesis and biological properties of benzimidazole inhibitors of the DNA repair enzyme poly(ADP-ribose) polymerase. J. Med. Chem., 43, 4084-4097.

100. Hattori, K., Kido, Y., Yamamoto, H., et al. (2004) Rational approaches to discovery of orally active and brain-penetrable quinazolinone inhibitors of poly(ADP-ribose)polymerase. J. Med. Chem., 47, 4151-4154.

101. Kinoshita, T., Nakanishi, I., Warizaya, M., Iwashita, A., Kido, Y., Hattori, K. and Fujii, T. (2004) Inhibitor-induced structural change of the active site of human poly(ADP-ribose) polymerase. FEBS Lett., 556, 43-46.

102. Iwashita, A., Hattori, K., Yamamoto, H., et al. (2005) Discovery of quinazolinone and quinoxaline derivatives as potent and selective poly(ADP-ribose) polymerase-1/2 inhibitors. FEBS Lett., 579, 1389- 1393. 
103. Miyashiro, J., Woods, K. W., Park, C. H., et al. (2009) Synthesis and SAR of novel tricyclic quinoxalinone inhibitors of poly(ADP-ribose) polymerase-1 (PARP-1). Bioorg. Med. Chem. Lett., 19, 4050-4054.

104. Gandhi, V. B., Luo, Y., Liu, X., et al. (2010) Discovery and SAR of substituted 3-oxoisoindoline-4-carboxamides as potent inhibitors of poly(ADP-ribose) polymerase (PARP) for the treatment of cancer. Bioorg. Med. Chem. Lett., 20, 1023-1026.

105. Penning, T. D., Zhu, G. D., Gong, J., et al. (2010) Optimization of phenyl-substituted benzimidazole carboxamide poly(ADP-ribose) polymerase inhibitors: identification of (S)-2-(2-fluoro-4-(pyrrolidin-2-yl) phenyl)-1H-benzimidazole-4-carboxamide (A-966492), a highly potent and efficacious inhibitor. J. Med. Chem., 53, 3142-3153.

106. Gangloff, A. R., Brown, J., de Jong, R., et al. (2013) Discovery of novel benzo[b][1,4]oxazin-3(4H)-ones as poly(ADP-ribose)polymerase inhibitors. Bioorg. Med. Chem. Lett., 23, 4501-4505.

107. Lindgren, A. E., Karlberg, T., Thorsell, A. G., et al. (2013) PARP inhibitor with selectivity toward ADP-ribosyltransferase ARTD3/PARP3. ACS Chem. Biol., 8, 1698-1703.

108. Ye, N., Chen, C. H., Chen, T., et al. (2013) Design, synthesis, and biological evaluation of a series of benzo[de][1,7]naphthyridin-7(8H)-ones bearing a functionalized longer chain appendage as novel PARP1 inhibitors. J. Med. Chem., 56, 2885-2903.

109. Aoyagi-Scharber, M., Gardberg, A. S., Yip, B. K., Wang, B., Shen, Y. and Fitzpatrick, P. A. (2014) Structural basis for the inhibition of poly(ADPribose) polymerases 1 and 2 by BMN 673, a potent inhibitor derived from dihydropyridophthalazinone. Acta Crystallogr. F. Struct. Biol. Commun., 70, 1143-1149.

110. Papeo, G., Posteri, H., Borghi, D., et al. (2015) Discovery of 2-[1-(4,4-Difluorocyclohexyl)piperidin-4-yl]-6-fluoro-3-oxo-2,3-dihydro-1Hisoindole-4-carboxamide (NMS-P118): a potent, orally available, and highly selective PARP-1 inhibitor for cancer therapy. J. Med. Chem., 58, 6875N6898.

111. Fu, L., Wang, S., Wang, X., Wang, P., Zheng, Y., Yao, D., Guo, M., Zhang, L. and Ouyang, L. (2016) Crystal structure-based discovery of a novel synthesized PARP1 inhibitor (OL-1) with apoptosis-inducing mechanisms in triple-negative breast cancer. Sci. Rep., 6, 3 .

112. Thorsell, A. G., Ekblad, T., Karlberg, T., Löw, M., Pinto, A. F., Trésaugues, L., Moche, M., Cohen, M. S. and Schüler, H. (2017) Structural basis for potency and promiscuity in poly(ADP-ribose) polymerase (PARP) and tankyrase inhibitors. J. Med. Chem., 60, 1262-1271.
113. Langelier, M. F., Planck, J. L., Roy, S. and Pascal, J. M. (2011) Crystal structures of poly(ADP-ribose) polymerase-1 (PARP-1) zinc fingers bound to DNA: structural and functional insights into DNA-dependent PARP-1 activity. J. Biol. Chem., 286, 10690-10701.

114. Ali, A. A. E., Timinszky, G., Arribas-Bosacoma, R., Kozlowski, M., Hassa, P. O., Hassler, M., Ladurner, A. G., Pearl, L. H. and Oliver, A. W. (2012) The zinc-finger domains of PARP1 cooperate to recognize DNA strand breaks. Nat. Struct. Mol. Biol., 19, 685-692.

115. Langelier, M. F., Servent, K. M., Rogers, E. E. and Pascal, J. M. (2008) A third zinc-binding domain of human poly(ADP-ribose) polymerase-1 coordinates DNA-dependent enzyme activation. J. Biol. Chem., 283, $4105-4114$.

116. Tao, Z., Gao, P., Hoffman, D. W. and Liu, H. W. (2008) Domain C of human poly(ADP-ribose) polymerase-1 is important for enzyme activity and contains a novel zinc-ribbon motif. Biochemistry, 47, 5804-5813.

117. Naegeli, H., Loetscher, P. and Althaus, F. R. (1989) Poly ADPribosylation of proteins. Processivity of a post-translational modification. J. Biol. Chem., 264, 14382-14385.

118. D'Annessa, I., Coletta, A. and Desideri, A. (2014) Geometrical constraints limiting the poly(ADP-ribose) conformation investigated by molecular dynamics simulation. Biopolymers, 101, 78-86.

119. Lavalette, D., Tétreau, C., Tourbez, M. and Blouquit, Y. (1999) Microscopic viscosity and rotational diffusion of proteins in a macromolecular environment. Biophys. J., 76, 2744-2751.

120. Bonincontro, A., Calandrini, V. and Onori, G. (2001) Rotational and translational dynamics of lysozyme in water-glycerol solution. Colloids Surf. B: Biointerfaces, 21, 311-316.

121. Li, C., Wang, Y. and Pielak, G. J. (2009) Translational and rotational diffusion of a small globular protein under crowded conditions. J. Phys. Chem. B, 113, 13390-13392.

122. Levinthal, C. and Crane, H. R. (1956) On the unwinding of DNA. Proc. Natl. Acad. Sci. U. S. A., 42, 436-438.

123. Thomen, P., Bockelmann, U. and Heslot, F. (2002) Rotational drag on DNA: a single molecule experiment. Phys. Rev. Lett., 88, 248102.

124. Aubin, R. J., Fréchette, A., de Murcia, G., Mandel, P., Lord, A., Grondin, G. and Poirier, G. G. (1983) Correlation between endogenous nucleosomal hyper(ADP-ribosyl)ation of histone $\mathrm{H} 1$ and the induction of chromatin relaxation. EMBO J., 2, 1685-1693. 